\title{
Synthesis of a one-part geopolymer system for soil stabilizer using fly ash and volcanic ash
}

\author{
April Anne S. Tigue ${ }^{1}$, Jonathan R. Dungca ${ }^{2}$,Hirofumi Hinode ${ }^{3}$, Winarto Kurniawan ${ }^{3}$, and Michael Angelo B. Promentilla ${ }^{{ }^{*}}$ \\ ${ }^{1}$ Chemical Engineering Department, De La Salle University, Manila 1004, Philippines \\ ${ }^{2}$ Civil Engineering Department, De La Salle University, Manila 1004, Philippines \\ ${ }^{3}$ Department of Transdisciplinary Science \& Engineering, Tokyo Institute of Technology, Tokyo 152-8550, Japan
}

\begin{abstract}
A novel approach one-part geopolymer was employed to investigate the feasibility of enhancing the strength of in-situ soil for possible structural fill application in the construction industry. Geopolymer precursors such as fly ash and volcanic ash were utilized in this study for soil stabilization. The traditional geopolymer synthesis uses soluble alkali activators unlike in the case of ordinary Portland cement where only water is added to start the hydration process. This kind of synthesis is an impediment to geopolymer soil stabilizer commercial viability. Hence, solid alkali activators such as sodium silicate (SS), sodium hydroxide (SH), and sodium aluminate (SA) were explored. The influence of amount of fly ash (15\% and $25 \%$ ), addition of volcanic ash $(0 \%$ and $12.5 \%)$, and ratio of alkali activator SS:SH:SA (50:50:0, 33:33:33, 50:20:30) were investigated. Samples cured for 28 days were tested for unconfined compressive strength (UCS). To evaluate the durability, sample yielding highest UCS was subjected to sulfuric acid resistance test for 28 days. Analytical techniques such as X-ray fluorescence (XRF), X-ray diffraction (XRD), and scanning electron microscope/energy-dispersive X-ray spectroscopy (SEM/EDX) were performed to examine the elemental composition, mineralogical properties, and microstructure of the precursors and the geopolymer stabilized soil.
\end{abstract}

\section{Introduction}

Coal fly-ash, a by-product of coal-fired power plant, has known to have a natural pozzolanic property which can be utilized as substitute for ordinary Portland cement. In Philippines, Department of Energy (2015) has reported a coal consumption of 8.76 million metric tons in 2000 to 22.0 million metric tons in 2015 [1]. The tremendous increase in consumption pattern can be accounted to the use of coal as precursor for power generation, a major contributor to the country's total generation. In 2015, based on coal consumption statistics, $79.77 \%$ of coal is consumed by the power energy sector [2]. With the remarkable coal dependency for power generation, significant surge in the production of coal fly ash as waste by-product is expected. A significant amount of 1.14 MMT of coal fly ash generation has been reported by five major coal-fired powerplants in the Philippines [3]. Currently, a huge proportion of this waste go directly to landfill disposal. However, landfill disposal may pose threat as coal fly ash has been known to leach toxic heavy metals under certain conditions [4-6]. Similarly, volcanic ash or lahar which comprises volcanic material fragments such as pulverized rocks and minerals has also a natural pozzolanic property. Massive amount of volcanic material deposits was noted on the slope of Mt. Pinatubo amounting to approximately 5 to 6 cubic kilometres during its 1991 eruption [7]. These deposits being washed off downstream during heavy rain fall or typhoon is a major area of concern in the provinces of Central Luzon [8-9]. In fact, it has been reported that lahar flooding affects the river channels around the area. Due to a huge amount of by-product production and potential threat of lahar flooding, a need for potential utilization of these materials were studied.

Fly-ash and volcanic ash, a material rich in alumina silica, are promising precursors which can be used for soil stabilization through the process called geopolymerization. Geopolymerization involves dissolution of raw feedstock rich in aluminosilica in the presence an alkali activator to increase the reactivity. The aluminosilicate ions formed in the dissolution process will undergo polycondensation forming a gel matrix and will turn into a hardened molecule network. Factors such as sodium hydroxide concentration, alkali activator ratio, ash content, curing temperature and curing time are found to have influence in geopolymerization. The mechanism of geopolymerization can be described into three stages namely destruction-coagulation, coagulationcondensation, and condensation-crystallization [10].

\footnotetext{
Corresponding author: michael.promentilla@dlsu.edu.ph
} 
However, the traditional geopolymer synthesis which uses alkali activator solution is an impediment to geopolymer stabilized soil commercial viability. Hence, the researcher explored the one-part geopolymer synthesis. This kind of synthesis, instead of utilizing alkali activator solution, employs solid alkali activator. The synthesis involves dry mixing of solid alkali activators and geopolymer precursors, and addition of water. With the aid of 'just add water' concept like in the case of ordinary Portland cement to start the hydration process, its commercial viability will greatly increase [11-12].

In this study, the potential utilization of waste materials such as fly ash and volcanic ash, and use of solid alkali activator for soil stabilization were explored. The influence of amount of fly ash, addition of volcanic ash, and ratio of alkali activator on the unconfined compressive strength (UCS) of geopolymer stabilized soil were investigated using factorial design. To evaluate the durability, sample yielding highest UCS was subjected to sulfuric acid resistance test. X-ray diffraction (XRD), and scanning electron microscope/energy-dispersive X-ray spectroscopy (SEM/EDX) were performed to further analyse the structural and chemical changes after acid resistance test.

\section{Materials and Method}

\subsection{Sources of raw materials}

Fly ash samples were obtained from a coal fired power plant located at the central region of Luzon, Philippines and were used as received. The soil samples were obtained from a construction site located at the southern part of Manila, Philippines. Volcanic ash samples were collected from central region of Luzon, Philippines. The soil and volcanic ash samples were immediately sieved using Mesh No. 4 and stored in a container. Alkali activator used in the study are analytical grade of sodium silicate with composition $44 \% \mathrm{SiO}_{2}$, sodium hydroxide micropearls with $99 \%$ purity, sodium aluminate with 50 $56 \% \mathrm{Al}_{2} \mathrm{O}_{3} / 40-45 \% \mathrm{Na}_{2} \mathrm{O}$, and sulfuric acid with $95 \%$ purity were purchased from a local company.

\subsection{Characterization of raw materials}

Chemical analyses of fly ash, volcanic ash, and soil were conducted using techniques such as X-ray fluorescence dispersive (XRF), and X-ray diffractometer (XRD). Elemental analysis was performed by irradiating the sample with $\mathrm{X}$-ray beams generated from a voltage of 50 $\mathrm{kV}$ and current of $35 \mathrm{~A}$ using X-ray fluorescence (XRF) instrument (Shimadzu Model EDX-720). The crystalline phase of raw materials was determined using Multiflex Rigaku Automated Powder X-ray Diffractometer $\left(\lambda_{\mathrm{Cu} \mathrm{Ka}}\right.$ $=1.54 \AA$, Voltage $=40 \mathrm{kV}$, Current $=30.0 \mathrm{~mA}$ ) with a measuring angle of $5^{\circ}-60^{\circ}$. Particle size analysis was performed in accordance with ASTM D-422 using sieves to determine the particle size distribution of soil and volcanic ash [13]. In compliance with the standard method giving uniform spacing, a set of sieves 3-in, 11/2in, $3 / 4$-in, $3 / 8$-in, No. 4 , No. 8 , No. 16 , No. 30 , No. 50, No. 100, and No. 200 were used. For particle size analysis of fly ash, dynamic light scattering was considered with single exposure and a total exposure time of 10 seconds using sodium lauryl sulfate as solvent. Atterberg limit, which includes plastic limit and liquid limit of soil, was performed in accordance with ASTM D-4318 [14]. The soil type was determined based on unified soil classification using the data obtained from Atterberg limit and particle size distribution.

\subsection{Research design}

The influence of amount of fly ash, addition of volcanic ash, and ratio of alkali activator SS:SH:SA were explored in this study. For this reason, factorial design was chosen. The response variable considered in this experiment was unconfined compressive strength (UCS) of geopolymer stabilized soil. The controllable factors that were kept constant during the experiment were alkali activator/ash content $(30 \% \mathrm{w} / \mathrm{w})$, amount of water ( $8 \%$ of the soil), curing temperature (ambient temperature), and curing time (28 days) [15-17].

\subsubsection{Factor and levels}

The research design consisted of 2 sets of 6 factorial combinations to determine the influence of amount of fly ash $(\% \mathrm{w} / \mathrm{w})$, and alkali activator ratio (SS:SH:SA) and to determine the effect of adding volcanic ash $(\% / \mathrm{w} / \mathrm{w})$ on unconfined compressive strength (UCS) were investigated. Other parameters used in this experiment are shown in Table 1-2 [18-23].

Table 1. Design factors range and levels to determine the influence of amount of fly ash, and alkali activator ratio.

\begin{tabular}{|c|c|c|c|c|}
\hline $\begin{array}{c}\text { Design } \\
\text { Factor }\end{array}$ & $(-)$ & $(0)$ & $(+)$ & $\begin{array}{c}\text { Type of } \\
\text { Factor }\end{array}$ \\
\hline $\begin{array}{c}\text { Amount } \\
\text { of FA }\end{array}$ & $15 \%$ & - & $25 \%$ & Numerical \\
\hline $\begin{array}{c}\text { Alkali } \\
\text { activator } \\
\text { ratio }\end{array}$ & $50: 20: 30$ & $33: 33: 33$ & $50: 50: 50$ & Categorical \\
\hline
\end{tabular}

Table 2. Design factors range and levels to determine effect of adding volcanic ash.

\begin{tabular}{|c|c|c|c|c|}
\hline $\begin{array}{c}\text { Design } \\
\text { Factor }\end{array}$ & $(-)$ & $(0)$ & $(+)$ & $\begin{array}{c}\text { Type of } \\
\text { Factor }\end{array}$ \\
\hline $\begin{array}{c}\text { Amount } \\
\text { of VA }\end{array}$ & $0 \%$ & - & $12.5 \%$ & Numerical \\
\hline $\begin{array}{c}\text { Alkali } \\
\text { activator } \\
\text { ratio }\end{array}$ & $50: 20: 30$ & $33: 33: 33$ & $50: 50: 50$ & Categorical \\
\hline
\end{tabular}

\subsubsection{Statistical treatment of data}

The statistical technique used was ANOVA (analysis of variance). This can determine whether there is statistically significant difference in the obtained data of various experimental runs. p-value was chosen to 
determine the statistically significant difference. When p-value $<0.05$, amount of fly ash, addition of volcanic ash, and ratio of alkali activator are significant. Parameters such as coefficient of determination, adjusted coefficient of determination, predicted coefficient of determination, coefficient of variation, predicted residual sum of squares, and regression data were used to evaluate how well the model fits the data with the aid of Design Expert Software for better analysis.

\subsection{Soil stabilization}

Dry mixing of materials (mixture of fly ash, volcanic ash, and alkali activator) were performed according to the runs generated by the design considering the parameters listed in Table 1-2. Amount of water equivalent to $8 \%$ of the soil was added on the dry formula followed by mixing for at least 5 minutes. The geopolymer paste binder, a mixture of dry formula and water, was completely mixed with soil. After stabilization, geopolymer stabilized soil was compacted in a cylindrical mold $50 \mathrm{~mm}$ diameter by $100 \mathrm{~mm}$ height for 3 layers of about 25 tamps per layer. The molded specimen was sealed and cured for 28 days at ambient conditions. After curing, the unconfined compressive strength was determined using Digimax Plus automatic Uniframe compression tester.

\subsection{Sulfuric acid resistance test}

Specimen, prepared based on the parameters yielding highest UCS, was compacted in a cylindrical mold 50 $\mathrm{mm}$ diameter by $100 \mathrm{~mm}$ height and allowed to cure for 28 days. After curing, sample was immersed in 5\% $(\mathrm{w} / \mathrm{w})$ sulfuric acid solution $[17,24]$. The compressive strength was measured after 28 days of immersion. Soaked sample was further analysed using XRD and SEM/EDX. The sample for XRD analysis were pulverized in powdered form and were sent to Tokyo Institute of Technology. The samples for SEM/EDX analysis were obtained from the broken samples resulted from the destructive compressive test and were then sent to DOST-Admatel. Samples, coated with gold, were analysed using Field-emission scanning electron microscope (voltage $=2.0 \mathrm{kV}$ and beam current $=43 \mathrm{pA}$ ) equipped with Energy-dispersive X-ray spectroscopy with a voltage of $15.0 \mathrm{kV}$ and beam current of $0.69 \mathrm{nA}$.

Table 3. Chemical composition of soil, fly ash and volcanic ash.

\begin{tabular}{|c|c|c|c|}
\hline $\begin{array}{c}\text { Chemical } \\
\text { Compound }\end{array}$ & $\begin{array}{c}\text { Soil } \\
(\% \mathrm{wt})\end{array}$ & $\begin{array}{c}\text { Fly Ash } \\
(\% / w t)\end{array}$ & $\begin{array}{c}\text { Volcanic } \\
\text { Ash (\%/wt) }\end{array}$ \\
\hline $\mathrm{SiO}_{2}$ & 38.87 & 24.65 & 56.75 \\
\hline $\mathrm{Fe}_{2} \mathrm{O}_{3}$ & 34.06 & 44.63 & 13.00 \\
\hline $\mathrm{Al}_{2} \mathrm{O}_{3}$ & 12.53 & 8.55 & 11.34 \\
\hline $\mathrm{CaO}$ & 6.82 & 16.04 & 10.93 \\
\hline $\mathrm{TiO}_{2}$ & 3.09 & 1.32 & 1.35 \\
\hline $\mathrm{K}_{2} \mathrm{O}$ & 1.87 & 1.18 & 5.01 \\
\hline $\mathrm{SO}_{3}$ & - & 1.63 & - \\
\hline
\end{tabular}

\section{Results and discussion}

\subsection{Raw material characterization}

\subsubsection{Soil}

Soil used in this work was classified as brown silty sand (SM) in accordance with unified soil classification system. The results of liquid limit, plastic limit and plasticity index showed that the fines are non-plastic and had a specific gravity of 2.54 . Soil particles has a cloudy and an irregular honeycomb like structure as presented in Figure 1. The particle size distribution is shown in Figure 2. This illustrates that the median diameter $\left(D_{50}\right)$ is $0.70 \mathrm{~mm}$. The elemental analysis of soil in oxides form, conducted by ITDI-DOST is shown in Table 3. It is primarily composed of $\mathrm{SiO}_{2}, \mathrm{Fe}_{2} \mathrm{O}_{3}, \mathrm{Al}_{2} \mathrm{O}_{3}$, and $\mathrm{CaO}$. The mineralogical phase also showed presence of $\mathrm{Si}$ and $\mathrm{Al}$ as shown in Figure $3 \mathrm{a}$ wherein it contains quartz $\left(\mathrm{SiO}_{2}\right)$, cristobalite $\left(\mathrm{SiO}_{2}\right)$, montmorillonite $\left((\mathrm{Na}, \mathrm{Ca})_{0.3}(\mathrm{Al}, \mathrm{Mg})_{2} \mathrm{Si}_{4} \mathrm{O}_{10}(\mathrm{OH})_{2} \cdot \mathrm{nH}_{2} \mathrm{O}\right)$, and magnetite $\left(\mathrm{Fe}_{3} \mathrm{O}_{4}\right)$.

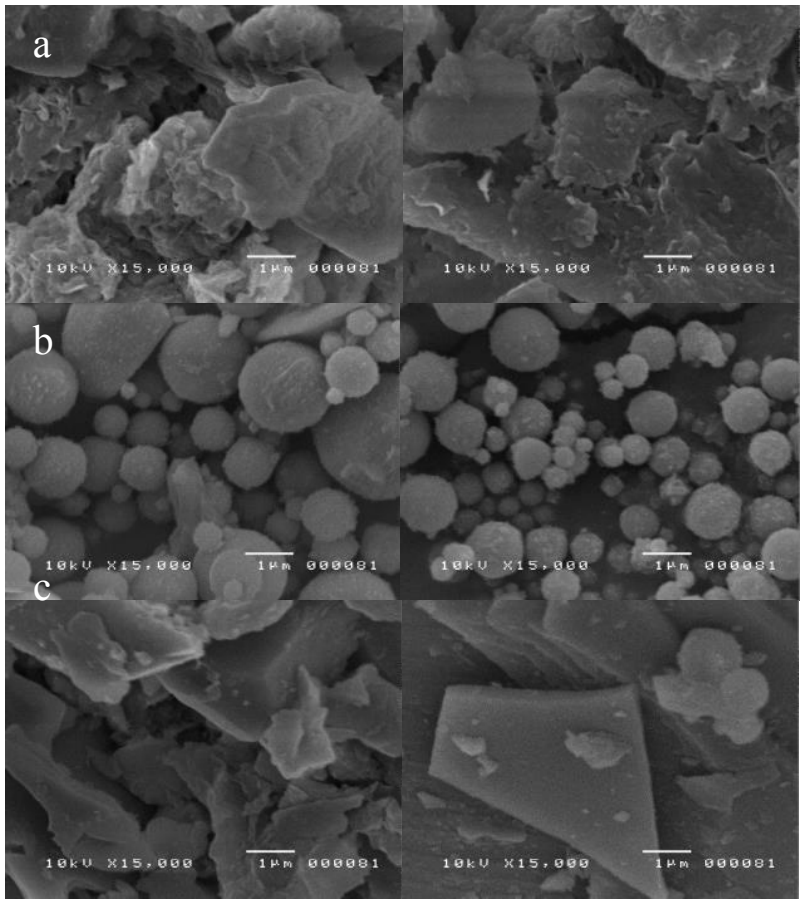

Fig. 1. SEM images of a) soil, b) fly ash, and c) volcanic ash.

\subsubsection{Fly ash}

Fly ash is classified as ASTM class F fly ash or lowcalcium fly ash considering that the total $\mathrm{SiO}_{2}, \mathrm{Al}_{2} \mathrm{O}_{3}$, and $\mathrm{Fe}_{2} \mathrm{O} 3$ is more than $70 \%$. It is primarily composed of $\mathrm{SiO}_{2}, \mathrm{Fe}_{2} \mathrm{O}_{3}, \mathrm{CaO}$, and $\mathrm{Al}_{2} \mathrm{O}_{3}$ with median particle size of 1.92 microns as shown in Figure 2. Morphological characteristics of fly ash showed non-uniform spherical particle as illustrated in Figure 1. XRD pattern of fly ash revealed the presence of quartz $\left(\mathrm{SiO}_{2}\right)$, mullite $\left(2 \mathrm{Al}_{2} \mathrm{O}_{3} \mathrm{SiO}_{2}\right)$, hematite $\left(\mathrm{Fe}_{2} \mathrm{O}_{3}\right)$, and magnetite $\left(\mathrm{Fe}_{3} \mathrm{O}_{4}\right)$. as shown in Figure $3 \mathrm{~b}$. 


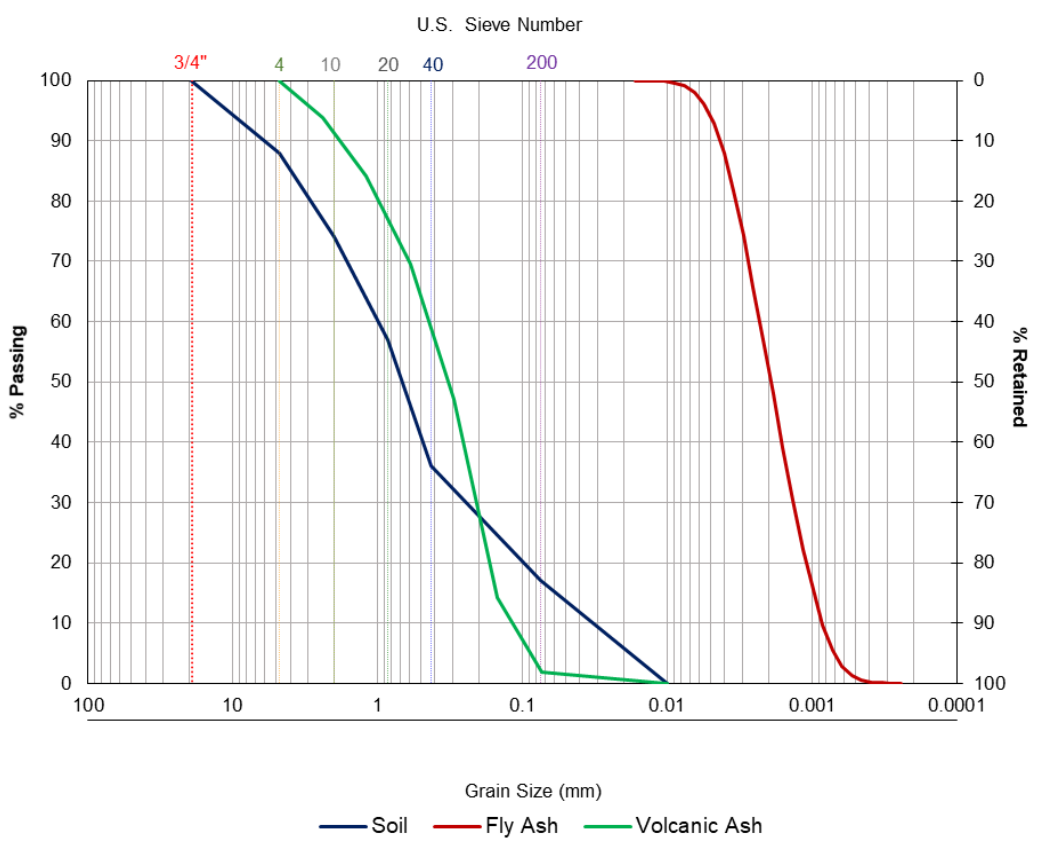

Fig. 2. Particle size distribution of soil, fly ash and volcanic ash.
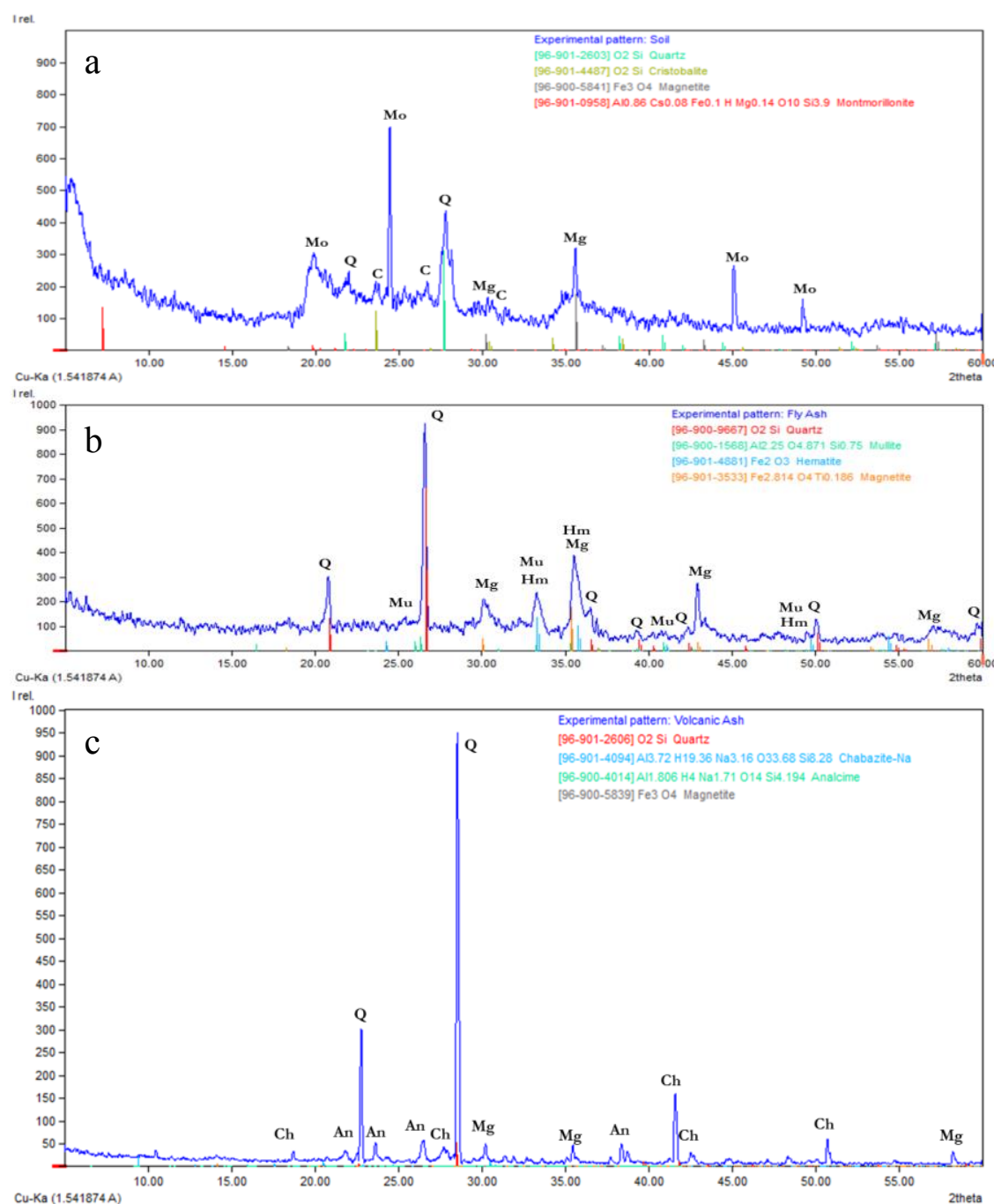

Fig. 3. XRD pattern of a) soil (Mo- Montmorillonite; Q- Quartz; C- Cristobalite; MgMagnetite); b) Fly Ash (Q- Quartz; Mu- Mullite; Hm-Hematite; Mg- Magnetite); and c) Volcanic Ash (Q- Quartz; A- Analcime; Ch- Chabazite; Mg- Magnetite). 


\subsubsection{Volcanic ash}

Volcanic ash primarily comprises $\mathrm{SiO}_{2}, \mathrm{CaO}, \mathrm{Al}_{2} \mathrm{O}_{3}$, and $\mathrm{Fe}_{2} \mathrm{O}_{3}$. The particle size distribution of volcanic ash is shown is Figure 2. It is observed that $50 \%$ of the particles has a diameter of $0.33 \mathrm{~mm}$. Morphology of volcanic ash particles consists irregular flaky with angular edges as illustrated in Figure 1. The result of $\mathrm{XRD}$ also showed presence of crystalline phases such as quartz $\left(\mathrm{SiO}_{2}\right)$, analcime $\left(\mathrm{NaAlSi}_{2} \mathrm{O}_{6} \cdot \mathrm{H}_{2} \mathrm{O}\right)$, chabazite $\left(\left(\mathrm{Ca}, \mathrm{Na}_{2}, \mathrm{~K}_{2}, \mathrm{Mg}\right) \mathrm{Al}_{2} \mathrm{Si}_{4} \mathrm{O}_{12} \cdot 6 \mathrm{H}_{2} \mathrm{O}\right)$, and magnetite $\left(\mathrm{Fe}_{3} \mathrm{O}_{4}\right)$ (Figure 3c).

\subsection{Unconfined compressive strength}

Table 4-5 summarize the measured unconfined compressive strength of stabilized soil geopolymer at different combination of raw materials and alkali activator. The unconfined compressive strength of the stabilized soil geopolymer was observed to range from a minimum $45 \mathrm{kPa}$ to a maximum $971 \mathrm{kPa}$. The stabilized soil with $25 \%$ fly ash $/ 75 \%$ soil and alkali activator with $50 \% \mathrm{SH} / 50 \% \mathrm{SS}$ was measured to yield the highest value of unconfined compressive strength. As per requirement of National Structural Code of the Philippines, a compressive strength of at least $75 \mathrm{kPa}$ can be used for possible application in structural fill [25].

Table 4. Measured response (unconfined compressive strength) at varying amount of fly ash and alkali activator.

\begin{tabular}{|c|c|c|}
\hline $\begin{array}{c}\text { Amount of Fly } \\
\text { Ash (\%) }\end{array}$ & $\begin{array}{c}\text { Alkali Activator Ratio } \\
\text { (SS:SH:SA) }\end{array}$ & $\begin{array}{c}\text { UCS } \\
(\mathrm{kPa})\end{array}$ \\
\hline 15 & $50: 50: 0$ & 455 \\
\hline 25 & $50: 50: 0$ & 971 \\
\hline 15 & $50: 20: 30$ & 45 \\
\hline 25 & $50: 20: 30$ & 348 \\
\hline 15 & $33: 33: 33$ & 149 \\
\hline 25 & $33: 33: 33$ & 623 \\
\hline
\end{tabular}

Table 5. Measured response (unconfined compressive strength) at varying amount of volcanic ash and alkali activator.

\begin{tabular}{|c|c|c|}
\hline $\begin{array}{c}\text { Addition of } \\
\text { Volcanic Ash (\%) }\end{array}$ & $\begin{array}{c}\text { Alkali Activator Ratio } \\
\text { (SS:SH:SA) }\end{array}$ & $\begin{array}{c}\text { UCS } \\
(\mathrm{kPa})\end{array}$ \\
\hline 0 & $50: 50: 0$ & 971 \\
\hline 12.5 & $50: 50: 0$ & 745 \\
\hline 0 & $50: 20: 30$ & 348 \\
\hline 12.5 & $50: 20: 30$ & 242 \\
\hline 0 & $33: 33: 33$ & 623 \\
\hline 12.5 & $33: 33: 33$ & 421 \\
\hline
\end{tabular}

To statistically measure the influence of amount of fly ash, addition of volcanic ash, and alkali activator ratio using varying combination of parameters, experimental data shown in Table 4-5 were analysed using ANOVA (analysis of variance). Results from the statistical analysis showed that the amount of fly ash, and ratio of alkali activator have significant effect on unconfined compressive strength as shown in Table 6-7 (p-value of 0.0221 and 0.0445). Additionally, presence of volcanic ash in the geopolymer matrix is found to significantly affect the strength of geopolymer stabilized soil having a p-value of 0.0399 . The measured response fitted significantly, with a p-value of 0.0336 and 0.0162 , in both models. Furthermore, the resulting adjusted coefficient of determination of the models were calculated to be $94.36 \%$ (amount of fly ash) and $97.29 \%$ (addition of volcanic ash), respectively.

Table 6. Measured p-value at varying amount of fly ash and alkali activator.

\begin{tabular}{|c|c|c|}
\hline Source & $\begin{array}{c}\mathrm{p} \text { value } \\
(\mathrm{Prob}>\mathrm{F})\end{array}$ & \\
\hline Model & 0.0336 & significant \\
\hline Amount of fly ash (FA) & 0.0221 & significant \\
\hline Alkali Activator Ratio & 0.0445 & significant \\
\hline
\end{tabular}

Table 7. Measured p-value at varying amount of volcanic ash and alkali activator.

\begin{tabular}{|c|c|c|}
\hline Source & $\begin{array}{c}\mathrm{p} \text { value } \\
(\text { Prob }>\mathrm{F})\end{array}$ & \\
\hline Model & 0.0162 & significant \\
\hline $\begin{array}{c}\text { Amount of volcanic ash } \\
\text { (VA) }\end{array}$ & 0.0399 & significant \\
\hline Alkali Activator Ratio & 0.0124 & significant \\
\hline
\end{tabular}

The final equation for the unconfined compressive strength were found to be:

Alkali Activator ratio (50SS:50SH:0SA)

$$
\begin{gathered}
U C S=-149+\left(43.10^{*} F A\right) \\
U C S=947-\left(14.24^{*} V A\right)
\end{gathered}
$$

Alkali Activator ratio (50SS:20SH:30SA)

$$
\begin{gathered}
U C S=-665+\left(43.10^{*} F A\right) \\
U C S=384-(14.24 * V A)
\end{gathered}
$$

Alkali Activator ratio (33SS:33SH:33SA)

$$
\begin{gathered}
U C S=-476+\left(43.10^{*} F A\right) \\
U C S=611-(14.24 * V A)
\end{gathered}
$$

The coefficients show the magnitude effect of factors on unconfined compressive strength. Equations 1, 3, and 5 show that high levels of amount of fly ash will result in an increase in compressive strength while equations 2,4 , and 6 show that high levels of amount of volcanic ash will result in the reduction of compressive strength. An increase in the amount of fly ash relative to the amount of volcanic ash could result to an increase in compressive strength. This may be attributed to the reactivity of the precursor in which particle size is a major factor $[17,26]$. Finer particles of fly ash may be an advantage as compared to the particle size of volcanic ash. Thus, increasing the amount of fly ash, more reactive source of aluminosilica in the precursor, could lead to a higher value of compressive strength. 


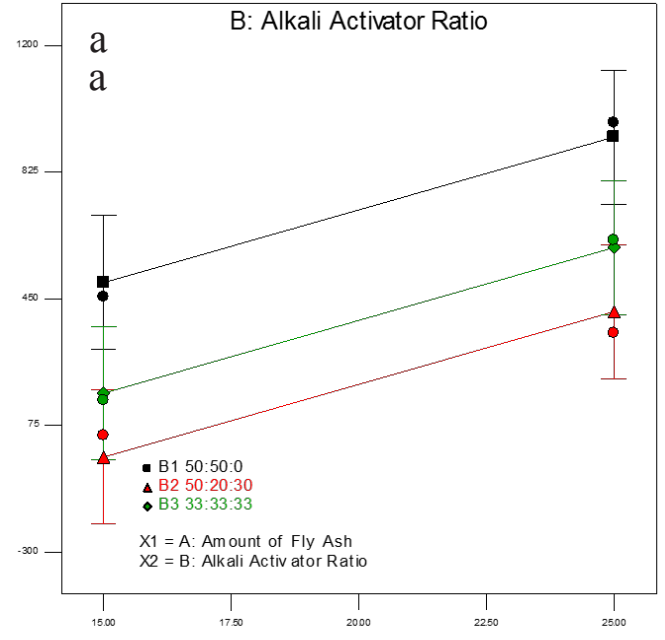

X1: A: Amount of Fly Ash X2: UCS

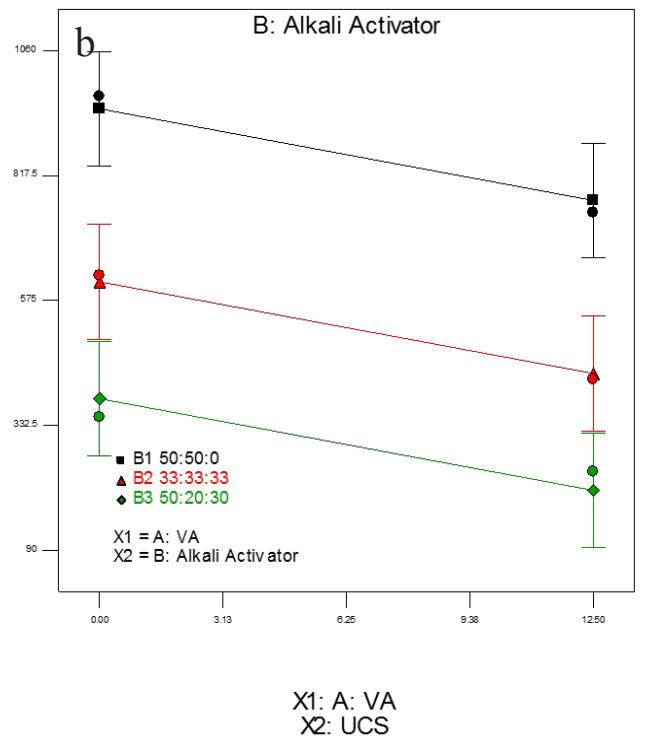

Fig. 4. Contour plot of a) fly ash and alkali activator; b) volcannic ash and alkali activator.

The increase in compressive strength of geopolymer stabilized soil have been remarkably noticed in alkali activator containing 50\%SS:50\% $\mathrm{SH}$ as shown in Figure 4. The model suggests that as the amount of sodium hydroxide increases, the strength of the stabilized soil tends to increase. Low amount of sodium hydroxide in the alkali activator, $<20 \%$, at varying amount of fly ash and volcanic ash could lead to a low strength stabilized soil. The production of low strength stabilized soil could be attributed to a lower dissolution rate, less leaching of alumina and silica ions from the precursor, thus lower value of compressive strength [16].

On the other hand, controlling the amount of sodium aluminate could produce a high strength stabilized soil considering higher amount of fly ash is present in the precursor and as long as more sodium hydroxide is present in the alkali activator. A greater proportion of sodium aluminate relative to the amount of sodium hydroxide in the alkali activator could lead to a low strength stabilized soil geopolymer. This may be due to the increase in amount of alumina source and decrease in amount of silica source since at low amount of sodium hydroxide, less leaching of silica is anticipated [23]. Additionally, geopolymer produced with more silica tend to have higher values of compressive strength [27]. Thus, for this case, low amount of silica relative to the alumina could produce a low strength stabilized soil geopolymer.

\subsection{Sulfuric acid resistance}

The strength of geopolymer stabilized soil was observed to increase when exposed in acidic medium. The unsoaked specimen was measured with strength of 971 $\mathrm{kPa}$ while the compressive strength of soaked specimen exposed in $5 \%(\mathrm{w} / \mathrm{w})$ sulfuric acid solution for 28 days was measured with strength of $2620 \mathrm{kPa}$. The increase in strength may be attributed by the influence of curing time considering that the gel matrix seems to be not affected by acid attack. A longer soaking time could mean an increase also with the curing time prior unconfined compressive test. The unreacted aluminosilica and alkali activator might continue to undergo geopolymerization resulting to an increase of strength over time [13]. Thus, the increase in strength of soaked specimen showed that geopolymer stabilized soil is resistant to acid attack.

\subsection{Mineralogical properties}

Raw materials such as soil and fly ash were observed to have sharp diffraction peak of quartz as shown in Figure 5. Significant mineralogical change has been demonstrated between soil, fly ash, unsoaked specimen, and soaked specimen. The notable decrease in peaks of quartz as depicted in Figure 5 shows the dissolution of crystalline phase results to an increase in reactivity. On the other hand, formation of new crystals such as anorthite (calcium tecto-dialuminodisilicate) and dolomite (calcium magnesium carbonate) for unsoaked specimen was observed. Also, presence of an iron rich crystals, magnetite, was also expected given that the soil and fly ash contain a significant amount of iron as revealed by the XRF result. After immersion in sulfuric acid solution, soaked specimen showed a change in mineralogical property where sharp peaks of gypsum were observed at $11.60^{\circ}$ and $20.70^{\circ} 2 \theta$, respectively. Presence of gypsum may be related to the reaction between the free calcium in the geopolymer matrix and the sulfuric acid solution [17]. The peaks of gypsum clearly demonstrate that unreacted calcium compounds can be easily attacked by an acid. Additionally, disappearance of anorthite peaks and decrease in peak intensity of quartz in unsoaked specimen may be attributed to the dissolution of crystalline phases. This results to an increase in amorphous state thereby increasing the reactivity of these compounds for further geopolymerization [28]. 


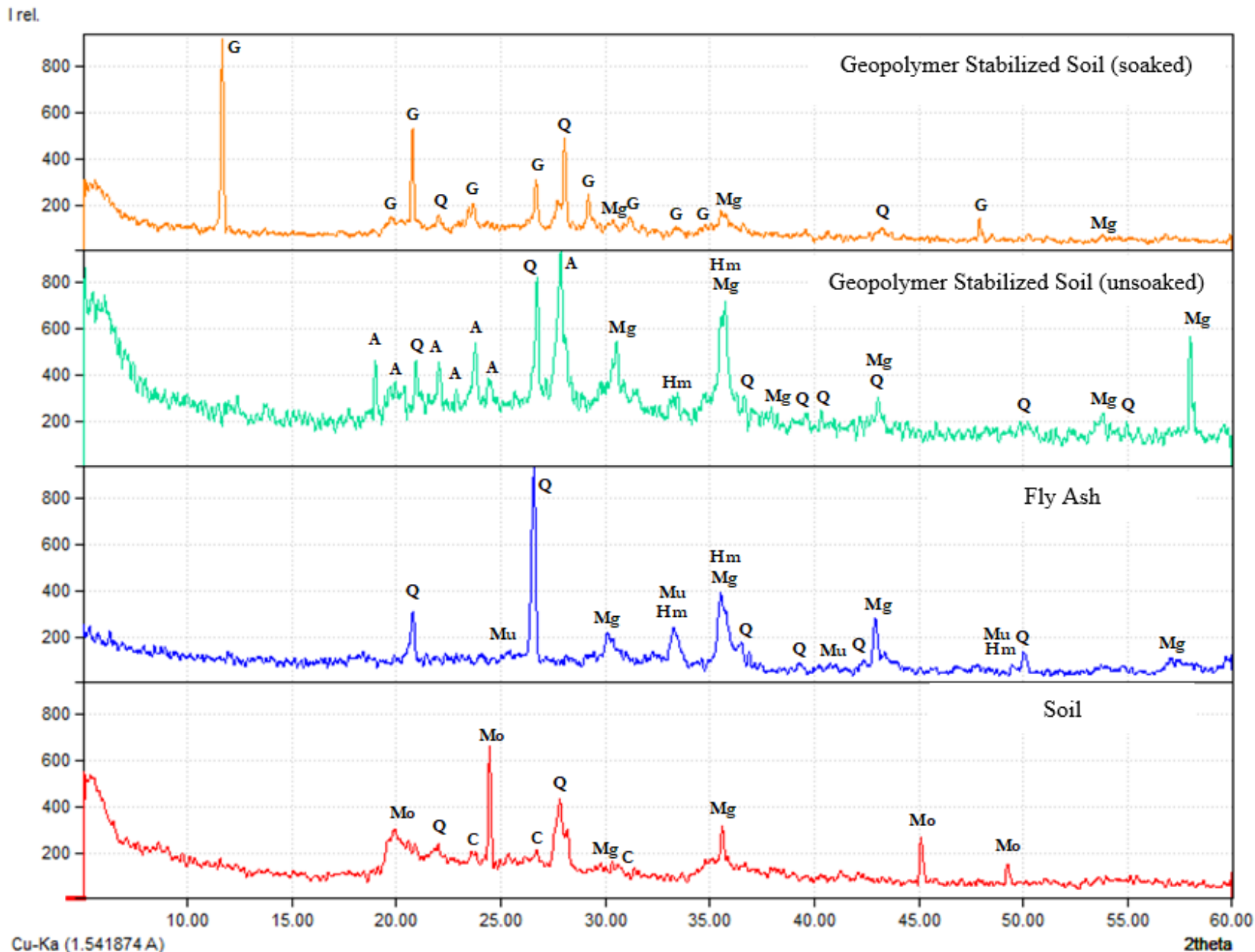

Fig. 5. XRD comparative analysis of raw materials and stabilized soil geopolymer (Q- Quartz; Hm-Hematite; MuMullite; Mg- Magnetite; Mo- Montmorillonite; C- Cristobalite; G- Gypsum; A-Anorthite).

\subsection{Microstructure properties}

Morphological characteristics of soaked and unsoaked stabilized soil geopolymer was carried out using SEM/EDX analysis as shown in Figure 6. Geopolymeric gel microstructure were also investigated for both samples by comparing its composition based on EDX spectra. The SEM images of samples unsoaked specimen was clearly observed to contain a number of spherical particles similar to morphology of fly ash. This may correspond to unreacted reacted fly ash in the sample. The specimen as shown in Figure 6 was also observed to be partially polymerize due to the partial covering of fly ash particles in the matrix. The particles were also noted to have large voids and pores. Additionally, presence of fibrous crystals and flower like structures are clearly seen. Small spongy particles were also visible covering the spherical particles. This structure resembles the morphology of magnetite. This is consistent with the XRD pattern of unsoaked specimen which showed diffraction peaks of magnetite in Figure 5.
On the other hand, soaked specimen evidently contains lesser amount of unreacted fly ash resulting to a homogenous phase structure as illustrated in Figure 7. The sample also appears to be well compacted and cemented leading to smaller voids and pores on the morphology. A needle like structure from a broken sphere was also observed. This may indicate partial dissolution of fly ash, thus exposing the smaller particles. Moreover, a hexagonal shape structures were also evident in the sample as shown in Figure 8. As confirmed by the EDX analysis, these structures are rich in calcium and sulfur. Formation of crystal rich in calcium and sulfur is an indication of gypsum in the matrix. The formation of gypsum is a result of reaction between free $\mathrm{Ca}^{2+}$ ions in the specimen and the free $\mathrm{SO}_{4}{ }^{-}$ ${ }^{2}$ ion in the acidic medium. The free $\mathrm{Ca}^{2+}$ ions in the specimen was noted to be directly attacked by the acidic medium and the matrix rich in $\mathrm{Na}$ gel was found to be resistant with no indication of sulfur in the EDX analysis. The evidence of gypsum formation was also observed in the result of XRD pattern of soaked specimen in Figure 5. 

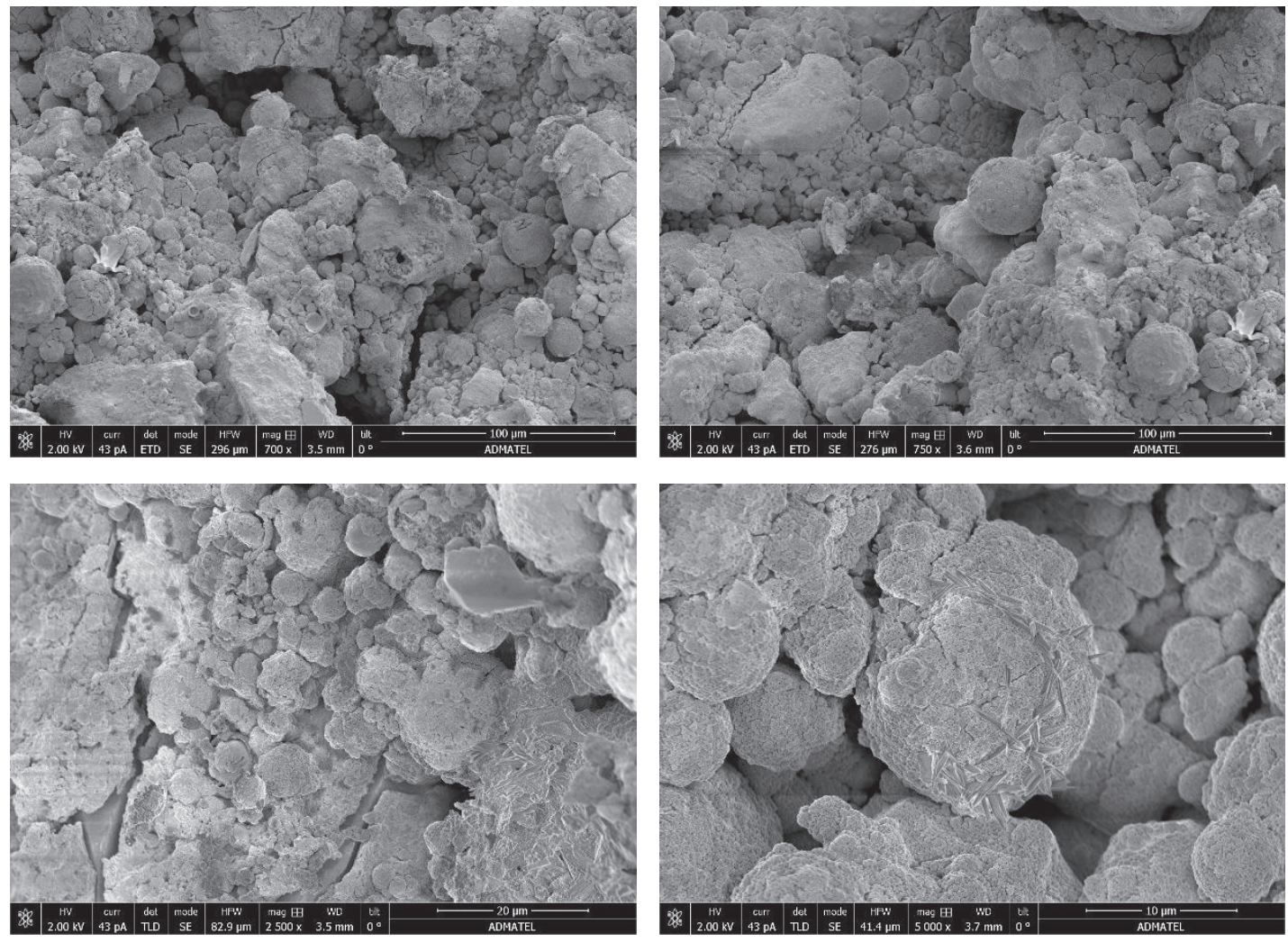

Fig. 6. SEM images of unsoaked pecimen.
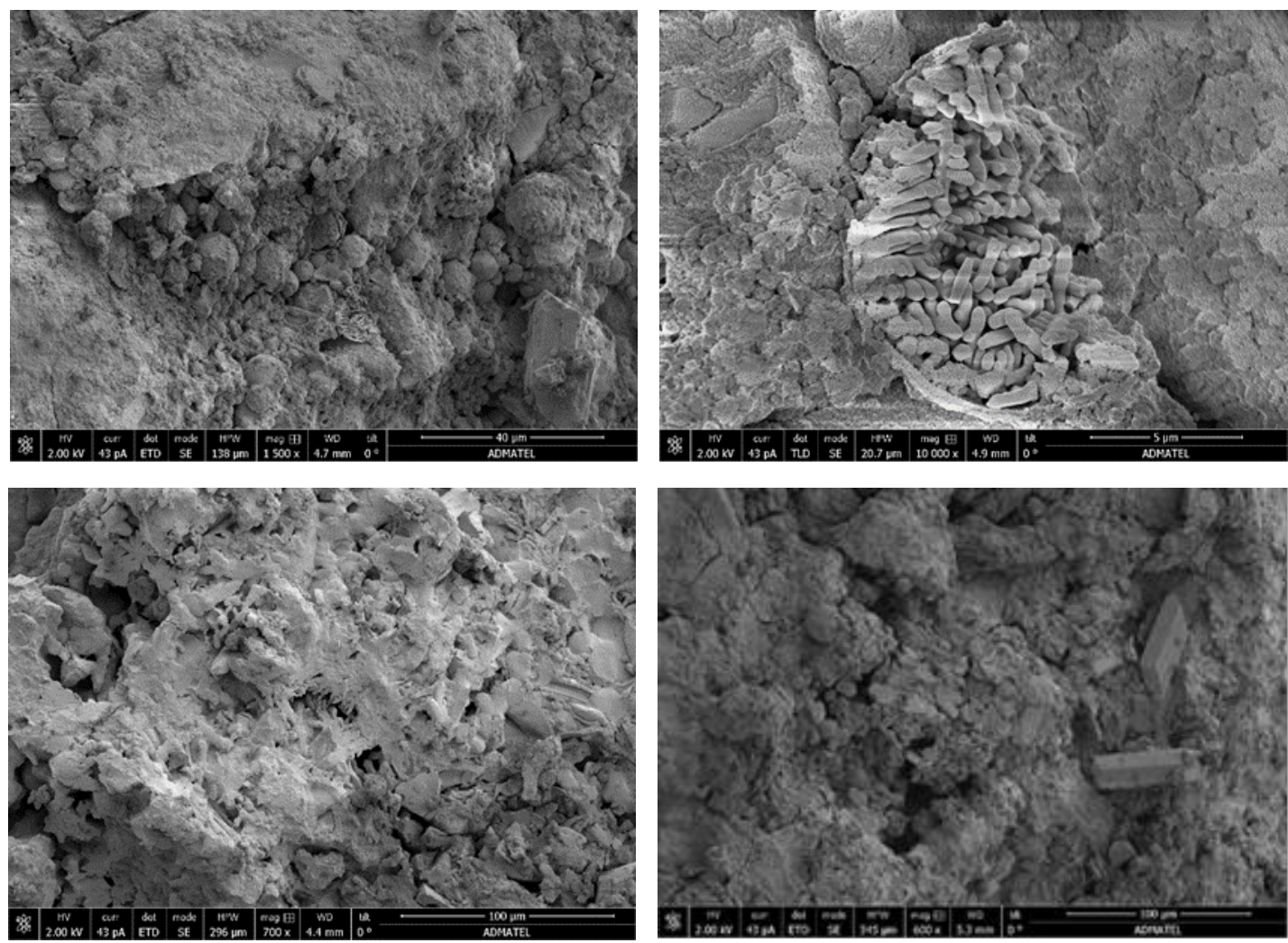

Fig. 7. SEM images of soaked specimen. 

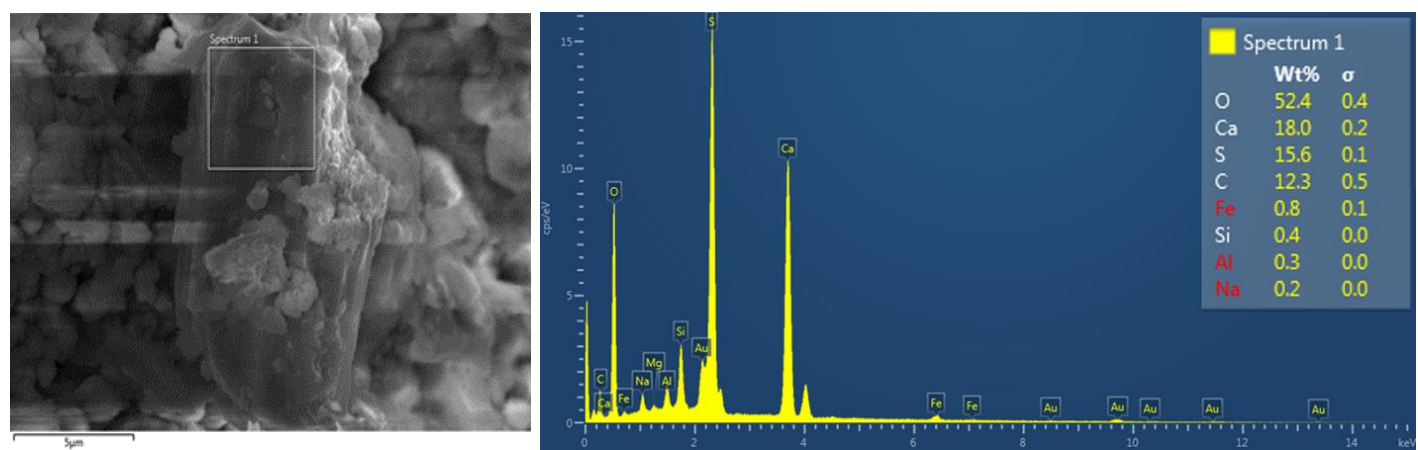

Fig. 8. SEM/EDX analysis of gypsum in soaked specimen.

The gel formation EDX analysis of stabilized soil geopolymer for both unsoaked and soaked specimen are shown in Table 8 and Figure 9. The elemental analysis of both specimen predominantly consists of $\mathrm{Na}, \mathrm{Ca}, \mathrm{Fe}$, $\mathrm{Si}, \mathrm{Al}, \mathrm{O}$, and $\mathrm{C}$. The molar ratios are calculated to be $\mathrm{Na} / \mathrm{Al}=2.05, \mathrm{Si} / \mathrm{Al}=2.64, \mathrm{Na} / \mathrm{Si}=0.78, \mathrm{Ca} / \mathrm{Si}=0.11$, and $\mathrm{Fe} / \mathrm{Si}=0.57$ for unsoaked specimen. Similarly, the composition of the gel of soaked specimen in terms of molar ratios of $\mathrm{Na} / \mathrm{Al}, \mathrm{Si} / \mathrm{Al}, \mathrm{Na} / \mathrm{Si}, \mathrm{Ca} / \mathrm{Si}$, and $\mathrm{Fe} / \mathrm{Si}$ are $1.11,2.83,0.39,0.06$, and 0.17 , respectively. These composition of gel resembles a typical poly(ferrosialate-disiloxo) type of binder with a formula relatively close to $[\mathrm{Ca}, \mathrm{Na}, \mathrm{K}, \mathrm{Mg}]-[-\mathrm{Fe}-\mathrm{O}-]_{\mathrm{x}}-[\mathrm{Si}-\mathrm{O}-\mathrm{Al}-\mathrm{O}-]_{1-\mathrm{x}}-[-$ $\mathrm{Si}-\mathrm{O}-$ ] having values of $\mathrm{x}$ less than or equal to 0.5 , and a value of y between 0 and $25[29,30]$. This is an evidence that the iron component of the raw materials participated in geopolymerization. This is consistent with the result of XRD analysis wherein peak intensities of iron rich crystals was decreased.

Table 8. EDX Analysis of gel formation.

\begin{tabular}{|c|c|c|c|c|c|c|c|c|c|c|c|c|}
\hline \multirow{2}{*}{ Specimen } & \multicolumn{10}{|c|}{ Composition (wt\%) } & \multicolumn{7}{c|}{ Molar Ratio } \\
\cline { 2 - 14 } & $\mathrm{Na}$ & $\mathrm{Ca}$ & $\mathrm{Si}$ & $\mathrm{Al}$ & $\mathrm{Fe}$ & $\mathrm{O}$ & $\mathrm{C}$ & $\mathrm{Na} / \mathrm{Al}$ & $\mathrm{Si} / \mathrm{Al}$ & $\mathrm{Na} / \mathrm{Si}$ & $\mathrm{Ca} / \mathrm{Si}$ & $\mathrm{Fe} / \mathrm{Si}$ \\
\hline $\mathrm{G} 1$ & 6.3 & 1.5 & 9.9 & 3.6 & 11.3 & 38.8 & 26.8 & 2.05 & 2.64 & 0.78 & 0.11 & 0.57 \\
\hline $\mathrm{G} 2$ & 5.5 & 1.4 & 17.1 & 5.8 & 5.8 & 48.8 & 13.6 & 1.11 & 2.83 & 0.39 & 0.06 & 0.17 \\
\hline
\end{tabular}
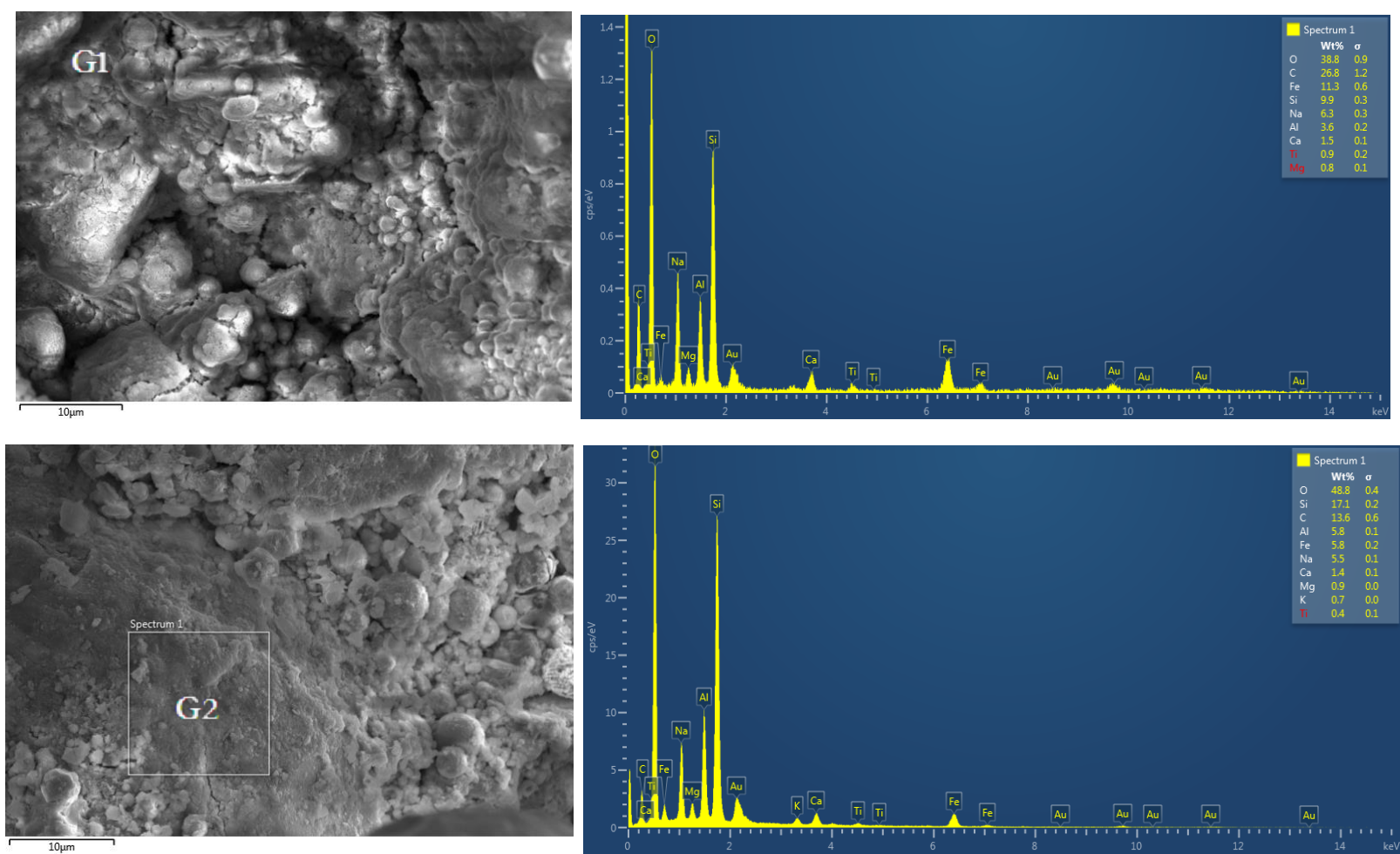

Fig. 9. EDX analysis of gel formation of unsoaked specimen $(\mathrm{G} 1)$ and soaked specimen $(\mathrm{G} 2)$. 


\section{Conclusion}

This study has explored the use of geopolymer precursors such as fly and volcanic ash with solid alkali activators such as sodium silicate, sodium hydroxide, and sodium aluminate. The strength of geopolymer stabilized soil was observed to be affected by the amount of fly ash, addition of volcanic ash, and the ratio of alkali activator. Increasing the amount of fly ash resulted in an increase in compressive strength while addition of volcanic ash in geopolymer matrix resulted in the reduction of compressive strength. The significant difference in the morphological images between unsoaked specimen and soaked specimen acts as support on the increase in mechanical strength of stabilized soil geopolymer after immersion in acid solution. The latter which appears to be well compacted and cemented gives a higher value of unconfined compressive strength while the former evidently contains large voids and pores and a number of spherical particles corresponding to unreacted fly ash gives a lower value of unconfined compressive strength. Moreover, the gel matrix of soaked specimen has shown to be acid resistant as confirmed by the EDX analysis with no indication of sulfur. A hexagonal shape structures were also evident in the sample indicating gypsum formation as confirmed by EDX and XRD pattern. Also, the composition of gel matrix formed resembles a typical poly(ferro-sialate-disiloxo) type of binder. The decrease in peaks of XRD pattern was found to be a manifestation of geopolymerization.

The authors would like to acknowledge the financial support from Engineering Research and Development for Technology (ERDT), and URCO Research Project. We are also thankful for the laboratory facilities and support of International Development Engineering of Tokyo Institute of Technology (TIT), Mechanical Engineering Laboratory, Chemical Engineering Laboraroty, and Geotechnical Laboratory of De La Salle University (DLSU), Advanced Device and Materials Testing Laboratory (ADMATEL) of Department of Science and Technology. Dr. Promentilla also acknowledges the JSPS Bridge Fellowship Program (BR171401) for the financial support during the conduct of the study TIT, Japan

\section{References}

1. Department of Energy. Coal Statistics. Available online: http://www.doe.gov.ph (accessed on 19 September 2016).

2. Department of Energy. Power Situation. Available online: http://www.doe.gov.ph (accessed on 19 September 2016).

3. S. Gallardo, J. Dungca, R. Gallardo, M. Kalaw, Sustainability Issues Due to Coal Ash from Coal Fired Power Plants Phase1: Impact Assessment of Coal Ash Dumping in a Typical Power Generating Facility; Interdisciplinary Research Final Report, (2012).

4. Ibrahim, Water Sci. 29, 109 (2015).
5. G. Akar, M. Polat, G. Galecki, U. Ipekoglu, Fuel Process. Technol. 104, 50 (2012).

6. N. Koukouzas, C. Ketikidis, G. Itskos, Fuel Process. Technol. 92, 441 (2011).

7. T. Orejas, Phivolcs: Pinatubo lahar threats not over, Inquirer.Net, 1(2015) Available online: http://newsinfo.inquirer.net (accessed on 19 September 2016).

8. I. O. Flora, Mudflow threat still present in Pampanga, Sunstar Pampanga, 1(2017) Available online : http://www.sunstar.com.ph (accessed on 30 June 2017).

9. Phivolcs, Phivolcs volcano monitoring, Philippine Institute of Volcanology and Seismology, 1(2009) Available online : http://www.phivolcs.dost.gov.ph (accessed on 30 June 2017).

10. A. Fernández-Jiménez, A. Palomo, in Geopolymers, edited by J. L. Provis and J. S. J. van Deventer (Woodhead Publishing, 89, 2009).

11. P. Duxson, in Geopolymers, edited by J. L. Provis and J. S. J. van Deventer (Woodhead Publishing, 37, 2009).

12. B. Singh, G. Ishwarya, M. Gupta, S. K. Bhattacharyya, Constr. Build. Mater. 85, 78 (2015).

13. Standard Test Method for Particle-Size Analysis of Soils (ASTM International, West Conshohocken, PA, 2007).

14. Standard Test Methods for Liquid Limit, Plastic Limit, and Plasticity Index of Soils (ASTM International, West Conshohocken, PA, 2010).

15. P. Pavithra, M. S. Reddy, P. Dinakar, B. H. Rao, B. K. Satpathy, A. N. Mohanty, J. Clean. Prod. 133, 117 (2016).

16. C. Phetchuay, S. Horpibulsuk, A. Arulrajah, C. Suksiripattanapong, A. Udomchai, Appl. Clay Sci. 127-128, 134 (2016).

17. J. N. Y. Djobo, A. Elimbi, H. K. Tchakouté, S. Kumar, Constr. Build. Mater. 124, 606 (2016).

18. A. Fauzi, U. J. Fauzi, W. M. Nazmi, Procedia Eng. 54, 675 (2013).

19. R. A. Mozumder, A. I. Laskar, Comput. Geotech. 69, 291 (2015).

20. M. Zhang, M. Zhao, G. Zhang, P. Nowak, A. Coen, M. Tao, Appl. Clay Sci. 108, 199 (2015).

21. M. Z. N. Khan, F. U. A. Shaikh, Y. Hao, H. Hao, Constr. Build. Mater. 125, 809 (2016).

22. A. A. Aliabdo, A. E. M. A. Elmoaty, H. A. Salem, Constr. Build. Mater. 121, 694 (2016).

23. A. Hajimohammadi, J. L. Provis, J. S. J. van Deventer, Ind. Eng. Chem. Res. 47, 9396 (2008).

24. M. Jin, Z. Zheng, Y. Sun, L. Chen, Z. Jin, J. Non. Cryst. Solids 450, 116 (2016).

25. Association of Structural Engineers of the Philippines, National structural code of the Philippines 2015: Volume I building, towers, and other vertical structures. (Association of Structural Engineers of the Philippines, Inc., 1, 2015).

\footnotetext{
*Corresponding author: michael.promentilla@dlsu.edu.ph
} 
26. M. Zhang, M. Zhao, G. Zhang, D. Mann, K. Lumsden, M. Tao, Constr. Build. Mater. 124, 373 (2016).

27. F. Pacheco-Torgal, J. Castro-Gomes, S. Jalali, Constr. Build. Mater. 22, 1315 (2008).

28. L. Chen, Z. Wang, Y. Wang, J. Feng, Materials (Basel). 9, (2016).

29. J. Davidovits, Geopolymer Inst. Libr. 1 (2013).

30. S. Kumar, J. N. Yankwa Djobo, A. Kumar, S. Kumar, J. Build. Eng. 8, 172 (2016). 